\title{
A cultura e a crítica social pelo olhar do humor gráfico
}

\section{Titre : Culture et critique sociale pour le regard d'humour graphique}

Tatiane Aparecida Severino ${ }^{1}$ 


\section{Resumo}

O presente artigo analisa cartuns publicados no suplemento Anexo - integrante do jornal Diário do Paraná de 1976 a 77 - de autoria de Luiz Antônio Solda (Itararé - SP, 1952) e Luiz Carlos Rettamozo (São Borja RS, 1948) como parte de uma reflexão sobre o posicionamento do artista em relação à crítica social e política, e também à cultura como um meio de contestação contra o autoritarismo e à alienação. A ênfase recai para a década de 1970, momento contraditório, em certa medida, entre política e cultura. $O$ debate é fundamentado conceitualmente por Raymond Williams (1969) em sua explanação acerca das relações dos artistas face às discussões políticas e sociais de sua época, e suas postulações relativas à evolução do significado de cultura, em sentido linguístico e social. $O$ texto abre-se a uma discussão em torno dos aspectos culturais, sociais e políticos em confluência baseada no pressuposto da hibridação cultural de Néstor Garcia Canclini (2013). O pensamento que norteia este ensaio aborda o humor gráfico como uma forma de manifestação artística/cultural questionadora sobre as interações sociais e culturais que se mantém em consonância com o sistema político de sua época. Como metodologia, a análise dos cartuns então escolhidos se destaca no âmbito deste artigo no anseio de compreender o desenvolvimento de uma postura crítica, à luz de incongruências no campo sociocultural e político de um período de mudanças para a produção cultural e intelectual com a efervescência de uma indústria cultural, do consumo e da massificação.

Palavras-chave: Cultura; crítica social; humor gráfico; anos 1970.

\section{RÉSUMÉ}

Cet essai analyse caricatures publiées dans le supplément Anexo- membre du journal Diário do Paraná dans l'années 1976 et 77 - rédigé par Luiz Antonio Solda et Luiz Carlos Rettamozo, autour d'une réflexion sur la position de l'artiste dans le cadre de la critique sociale et politique, et aussi de la culture comme un moyen de défense contre l'autoritarisme et l'aliénation. l'accent ici est aux années 1970, un temps contradictoire dans certaine mesure, entre la politique et la culture. Ce débat est conceptuellement fondée par Raymond Williams (1969) dans sa réflexion sur les relations entre les artistes face à des discussions politiques et sociales de son temps, et ses postulations sur l'évolution de la signification de la culture dans le sens linguistique et social. Le texte ouvre également une discussion sur la confluence culturelle, sociale et politique fondé sur l'hypothèse d'hybridation culturelle par Néstor Garcia Canclini (2013). La pensée qui guide cet essai traite de l'humour graphique comme une forme d'expression artistique/culturel de questionnement sur des interactions sociales et culturelles qui reste en ligne avec le système politique de son temps. En tant que méthodologie, l'analyse des dessins alors choisis est soumis à cet article dans le désir de comprendre le développement d'une critique, à la lumière des incohérences dans le domaine socioculturel et politique d'une période de changement pour la production culturelle et intellectuelle avec effervescence d'une industrie culturelle, la consommation et la massification.

Mots-clés: Culture; critique sociale; humour graphique ; l'annès 1970.

ISSN: $2175-2346$

1 tatianesever@gmail.com 


\section{INTRODUÇÃO}

A reflexão que aqui se propõe tem como objeto de estudo dois desenhos de humor de autoria de Luiz Antônio Solda e Luiz Carlos Rettamozo respectivamente publicados no suplemento cultural Anexo - integrante do jornal curitibano Diário do Paraná entre 1976 e 1977. O primeiro - Solda - colaboraria de modo fixo no suplemento com trabalhos gráficos e textuais. Além do Anexo, atuaria como publicitário em agências da cidade, como desenhista de humor ganhou prêmios nos Salões de Humor de Piracicaba em 1975, 76 e 77. Rettamozo esteve à frente da direção de arte do suplemento, coordenava a coluna diária de humor Humordaça, lançada em maio de 1977 que apresentava desenhos de diversos artistas, tanto locais como nacionais, conhecidos do público ou não. Também atuou como artista, jornalista e publicitário. Colaborou no jornal alternativo Pólo Cultural, editado pela primeira vez em março de 1978 com grande parte da equipe do Anexo, quando este já havia encerrado suas atividades, além de outras publicações e revistas, muitas delas voltadas para questionamentos que tocavam a política e a sociedade de modo geral. Nas artes plásticas participou de algumas edições do Salão Paranaense, sendo premiado em 1975, 76 e 78, participou em 1977 da XIV Bienal Internacional de São Paulo.

De tal modo, ao voltarmos nossa atenção à atividade cultural no período autoritário brasileiro pós-1964, torna-se necessário considerar "[...] a convivência de uma intensa repressão política com um incentivo sem precedentes na produção de bens culturais [...]." (FREITAS, 2014, p. 28). Assim, dentro de uma dicotomia apoio/controle surgiriam aos olhos de determinados agentes culturais possibilidades de atuação nesse espaço complexo e ao mesmo tempo fechado, ou aparentemente fechado da produção artística. Esse modo de agir então dialogava tanto com a cultura de veia massiva quanto com outros ambientes estéticos desvinculados inicialmente de instituições culturais - os ditos marginais ou alternativos.

Fruto desse diálogo, espaços de interferência se abririam através de uma atuação que se poderia chamar de híbrida, no sentido mesmo de mescla, de quebra de barreiras, de confluências conceituais, como via de ampliação dos meios para inovações estéticas, culturais, políticas, sociais nos diversos cenários culturais. De tal modo, o desenho de humor parecia assumir uma importância relevante nesse processo de deslocamento e confluência entre fronteiras da expressão artística, sua linguagem oscilante entre massiva e transgressora - no sentido literal do termo - poderia nos dar uma ideia a respeito dessa intercessão em um sistema que se construía sobre redes de dominação e de influências verticalizadas sobre o cotidiano da sociedade.

Desse modo, ao seguir por um olhar sobre os desenhos então mencionados, com ênfase para suas características gráfico-visuais, este artigo busca tangenciar o modo como o artista se posiciona diante da crítica social ao tomar a própria cultura massiva como espaço de problematização em torno de contradições internas ao próprio meio. Além disso, procuramos discutir por quais caminhos gráficos e poéticos trilha a linguagem de humor como parte de questionamentos sociopolítico em face ao autoritarismo exercido no período militar brasileiro pós-1964.

Os pressupostos conceituais no tocante à cultura, tanto como forma de interação social como modo de manifestação crítica em relação às questões políticas, 
serão considerados fundamentalmente a partir da visão de dois teóricos que abordam o tema cultural inicialmente de modos distintos, mas que podem apresentar pontos de confluência intelectual no tocante ao posicionamento do sujeito artista diante das questões que rondam a experiência social. Trata-se então da ideia apresentada por Raymond Williams em "Cultura e Sociedade" (1969) onde discorre desde a formação linguística do termo cultura até o posicionamento de artistas/intelectuais em referência ao contexto político, assumindo então a cultura como mecanismo de questionamento de condutas e relações sociais estabelecidas. Noutra direção, a cultura e suas interações com outras instâncias da sociedade e da política, Canclini, em "Culturas Híbridas" (2013) sugere um fenômeno híbrido, inserido numa construção histórica, onde as combinações, e recombinações, entre estruturas sociais e culturais distintas, acabam por formar novas estruturas a partir de uma inter-relação que, segundo o autor, não está livre de contradições em seu âmbito interno, mas contribui para o reconhecimento da interculturalidade surgida no interior de sociedades diferentes durante o processo de modernização (CANCLINI, 2013, p. XVIII).

Numa visão mais clara desse conceito de hibridismo cultural, o autor define-o como a união entre processos e práticas socioculturais, antes separadas, para formar novas instâncias sociais (CANCLINI, 2013, p 20), ou seja, compreenderiam, num determinado sentido, as misturas entre o popular e o erudito, entre a instituição e a marginalidade para, através delas, criar novos modos de experimentar o tempo, as vivências estéticas, sociais, culturais. De tal modo, o desenho de humor, como uma linguagem que beiram alternativo, o marginal, de certa forma, assumir-se-ia como um meio capaz de deslocar-se entre ambientes que inicialmente não se comunicariam e, assim, estabeleceria choques, atritos, tensões entre eles, produzindo novas maneiras de perceber o cotidiano em torno e romper com a normalidade através de aberturas à problematização do sistema dominante.

Sendo assim, o artigo inicia com uma explanação sobre as ideias defendidas por Williams (1969) e Canclini (2013) em torno dos processos históricos e conceituais que conduziram a cultura, tanto em sentido linguístico/estrutural como social a uma configuração complexa e, por vezes, divergente em determinados aspectos quanto ao entendimento em torno de seu significado e constituição político-social. Nessa mesma via de discussão são inseridos autores brasileiros, como Hollanda (1981), Napolitano (2001) e Ortiz (2012), ambos com trabalhos voltados à cultura brasileira durante o regime militar como contraposição, ou mesmo, como reafirmação de pensamentos culturais.

Em seguida abordamos os desenhos de humor, já mencionados anteriormente, como parte dessa reflexão sobre a cultura e suas interações sociais, políticas, culturais, estéticas. Assume-se assim uma discussão dos processos de contestação e crítica social através da produção/difusão massiva da cultura, bem como da posição do artista/intelectual no âmbito político como questionador dos sistemas normativos que tendem a conduzir a sociedade a configurações passivas e alienadas face ao autoritarismo. 


\section{Interações culturais}

O campo cultural, pensado a partir de definições propostas por estudiosos culturais, aborda uma diversidade de debates e reflexões acerca de acepções que seguem uma miríade de pensamentos. Estes convergem de modo significativo a compreensões relativas às formas de relacionamento humano em sociedade, em analogia a debates políticos, econômicos e sociais. Porém, tais raciocínios se abrem a direções complexas e, por vezes, divergentes no tocante às definições dessas mesmas formas de relação social, observadas por diferentes pontos de vista.

Através da perspectiva adotada então por Williams (1969), é possível notar o tratamento dado ao termo "cultura", em significado atrelado com o de outros termos referentes a determinadas instâncias da construção da vida em sociedade como "indústria", "democracia", "classe" e "arte". Juntos esses cinco termos se relacionam com o desenvolvimento social, político e econômico em acompanhamento com os processos evolutivos também da linguagem.

É visível, em verdade, um padrão geral de mudança no uso dessas palavras e dele podemos valer-nos como de um especial sistema de referências, para reexaminar as modificações mais amplas da vida e de pensamento a que, evidentemente, correspondem as alterações de linguagem. (WILLIAMS, 1969, p. 15).

O autor discorre ainda sobre o entendimento quanto ao uso desses termos "indústria", "democracia", "classe" e "arte" -, o qual implicaria, presumivelmente, no emprego dado no cotidiano social. Desse modo assinala inclusive alterações que vão além da linguagem em si, ou seja, recaem sobre o próprio sistema econômico face à evolução no âmbito industrial, direcionando-se então para a questão da divisão da sociedade em classes, no estabelecimento da democracia e, por fim, na ligação com os campos cognoscíveis da arte e da própria cultura.

A evolução da palavra cultura dá testemunho de numerosas reações, importantes e continuadas, a essas alterações de vida social, econômica e política e pode ser encarada, em si mesma, como um especial tipo de roteiro, que permite explorar a natureza dessas mesmas alterações. (WILLIAMS, 1969, p. 18. Grifo do autor).

Ainda em acordo com tais ideias, seria possível sugerir o estabelecimento de uma rede de interações políticas, sociais, artísticas que configuraria uma espécie de "teia social". A cultura, tanto em sentido linguístico como em forma de interações em sociedade, passaria a ocupar um lugar central nessa "teia", uma vez que o desenvolvimento relativo ao seu uso reflete em reações nos campos político, social e econômico conforme revela a afirmação de Williams citada acima.

Por outro lado, as variações ocorridas no interior significante de tais termos associados pelo teórico inglês acabariam por gerar outros ainda (WILLIAMS, 1969). Nessa direção seria possível compreender tal fenômeno talvez como um processo híbrido de formação de conceitos e/ou termos designante das relações sociopolíticas. A confluência de significados implícitos nas palavras sugere, por assim dizer, modificações linguísticas que resultariam talvez em assuntos que tocam o sistema social em si, como resoluções políticas por exemplo. Estes por sua vez também sofreriam 
transformações internas e, por vezes, externas, que permitiriam estabelecer novos sistemas, novas maneiras de propor relacionamentos interpessoais.

Assim ao entender a cultura num sentido epistemológico, como um processo que reflete as transformações e complexidades no interior da vivência humana, em conexão com questões políticas e históricas, que tocaram ou tocam de alguma maneira a sociedade, como sugere Williams (1969, p. 19), seria pertinente tomar o fenômeno da crítica social e política ao regime militar no Brasil pós-1964 através da cultura ou de produções / ações culturais em confluência com outros modos de percepção da teia social, como um movimento que acabaria por gerar também transformações no interior da sociedade como um todo, acarretando em mudanças de posicionamento diante do sistema governamental em voga.

Sobre a ocorrência de hibridismos culturais, Canclini (2013, p. XIX) refere-se a tal como um processo onde as práticas ou estruturas culturais pré-existentes se combinam para formar outras, assim: "entendo por hibridação processos socioculturais nos quais estruturas ou práticas discretas, que existiam de forma separada, se combinam para gerar novas estruturas, objetos e práticas.". (CANCLINI, 2013, p. XIX. Grifo do autor). Nesse sentido o autor sugere ainda que as hibridações culturais podem ocorrer basicamente de duas formas, de modo planejado a partir da capacidade criativa individual ou coletiva, ou seja, na criação de novas mídias ou suportes para a veiculação de produções culturais, ou ainda, onde pode haver cruzamentos de saberes distintos na construção espaço-temporal. Por outro lado podem surgir hibridações não planejadas, decorrentes de fluxos migratórios, turísticos, etc. em que a cultura do lugar de origem se hibridiza com a do lugar de destino (CANCLINI, 2013, p. XXII). No entanto, o que importa no âmbito deste artigo, é a hibridação cultural no sentido da confluência entre diferentes formas de percepção sociocultural numa espécie de deslocamento por entre os mais diversos ambientes para, a partir de então, criar novos modos de comunicação, problematização, apreensão do espaço de vivência em comunidade ou particular.

Ao considerar o âmbito da cultura no período autoritário brasileiro seria passível talvez uma compreensão neste campo onde uma revisão das atitudes sócio-políticas face aos modos de produção cultural, de posicionamento crítico e de comunicabilidade entre diferentes setores culturais se revelaria interessante no sentido de busca por novas configurações e entendimentos na dimensão estética a partir de outros já existentes, para assim provocar choques, evidenciar as complexidades intrínsecas a um sistema que se construiria dentro de uma normalidade estabelecida. A problemática em torno de como agir culturalmente num ambiente autoritário, como o que se veria inserido então o país a partir do golpe em 1964, implicaria numa discussão em torno de novas concepções culturais, estéticas, sociais, políticas, econômicas que o regime acabaria por trazer para a sociedade de um modo geral.

Porém, em sentido estrito ao âmbito de uma crítica social, ou mesmo numa reflexão acerca do regime militar no Brasil em relação ao modo como este interferiu nas relações sociais, a cultura assumiria, numa determinada perspectiva, uma posição também de questionamento quanto ao momento vivido pela sociedade em geral. Com o cerceamento das liberdades expressivas, contrária ao sistema vigente, e dos próprios direitos civis, alguns movimentos culturais colocaram-se em atitude de 
contestação e resistência às imposições autoritárias vindas do governo. Na direção mesma da resistência através da arte Hollanda (1981) nos revela uma reflexão em torno do engajamento de artistas e literários, principalmente no âmbito da poesia, desde os anos 1960 com a tropicália ${ }^{1}$, até 1970, momento de contradições entre indústria cultural e resistência política, em oposição ao regime militar, afirma:

\begin{abstract}
A efervescência política e o intenso clima de mobilização que experimentávamos no dia-a-dia favoreciam a adesão dos artistas e intelectuais ao projeto revolucionário. Esse projeto, ao lado das contradições levantadas pelo processo de modernização industrial, configurado de forma acentuada a partir do período JK, emerge como referente de uma poesia que seja de vanguarda ou de dicção populista e traz para o centro de suas preocupações o empenho da participação social. (HOLLANDA, 1981, p. 15-16).
\end{abstract}

Dessa forma, uma possível compreensão aqui se voltaria para a postura crítica e reflexiva de pessoas envolvidas diretamente na cultura, seja como produtores ou mesmo como apoiadores de movimentos culturais, como um modo de contestação política, esta pertinente dentro das condições oferecidas pelo ambiente estabelecido no regime militar, onde o autoritarismo e a repressão passariam a compor de forma abrangente o cotidiano da população.

Com relação ainda ao contexto cultural nos anos 1970, de um modo geral, o movimento da contracultura marcou o início da década, mais especificamente o momento conhecido como "anos de chumbo", período de repressão mais intensa que iniciou com a promulgação do Ato Institucional n 5 (Al-5) em dezembro 1968, estendendo-se - os "anos de chumbo" - até meados de 1974, quando inicia o processo de distensão política proposta pelo General Ernesto Geisel (1907-1996) ao tomar posse como presidente em 1974, atuando até 1979, mesmo ano em que o Al-5 seria revogado.

A contracultura, então, configuraria sobretudo uma posição contestadora assumida principalmente por jovens e, também, por artistas e intelectuais inconformados de certa forma com a política repressiva e autoritária. Tal movimento fundava-se, em parte, na crítica à racionalização da vida através de atitudes comportamentais desviantes da norma padrão de conduta social. (COELHO, 2005, p. 39) Tomado num sentido amplo, a recusa a sistemas normatizados em geral, tanto no meio artístico como na própria vivência em sociedade, configurava-se numa das formas de reação contra o autoritarismo presente naquele momento.

O questionamento contracultural da racionalidade incidia nas mais diferentes dimensões da vida cotidiana. O caráter pluridimensional dessa prática social aparecia nas suas principais características: a ênfase na subjetividade em oposição ao caráter objetivo/racional do mundo exterior, a aproximação com a "loucura" e a marginalidade, a construção de comunidades alternativas. (COELHO, 2005, p 39. Grifo do autor).

\footnotetext{
1 A tropicália configurou-se num movimento que adensou a resistência ao regime por meio principalmente da música, tendo em artistas como Caetano Veloso e Gilberto Gil os principais representantes. "A preocupação com a atualização de uma linguagem 'do nosso tempo', já presente no concretismo, passa, a partir do tropicalismo, a ser aprofundada e relacionada a uma opção existencial.”. (HOLLANDA, 1981, p. 56).
} 
Assim a contracultura como um debate acerca das preocupações em relação ao corpo, a psicanálise, as drogas, acabaria por assumir uma perspectiva de mudança primeiramente interna, espiritual, para então agir em busca de transformações em âmbito social e político.

\begin{abstract}
São então esses elementos de crítica sugeridos pelo tropicalismo que serão intensificados nos anos seguintes, onde as preocupações com a modernidade e a desconfiança em relação à esquerda ortodoxa e à direita são aprofundadas, dando lugar a uma radicalização da crítica comportamental e a um novo tipo de atuação, já presente na tropicália, que privilegia a intervenção múltipla, "guerrilheira", diversificada e de tom anarquista nos canais do sistema. (HOLLANDA, 1981, p. 63. Grifo da autora).
\end{abstract}

Sobre o interesse político do artista numa construção histórica, voltamo-nos neste momento às objeções trazidas por Williams (1969, p. 144-171) onde relata sobre a relação mantida entre os poetas românticos William Blake (1757-1827), William Wordsworth (1770-1850), Percy Bysshe Shelley (1792-1822) e John Keats (1795-1821) com as questões sociais de sua época - entre os séculos XVIII e XIX - numa preocupação com a reflexão crítica sobre a sociedade. Tais escritores vivenciaram a experiência das Revoluções Francesa e Industrial onde uma agitação política marcaria o período. A posição dos poetas diante de tal problemática, social e política, não seria totalmente indiferente em sentido reflexivo (WILLIAMS, 1969, p. 53-54). Logo, revela-se interessante uma consideração conceitual quanto a uma fusão entre experiência e sentimentalismo, de um modo semelhante à configuração do movimento da contracultura no Brasil nos anos 1960 e 70 . A oposição ao sistema político e econômico demonstra, em última instância, um ponto de convergência entre intelectuais e artistas em consonância com a sociedade em momentos históricos distintos.

Ainda na esfera cultural brasileira na década de 1970, contudo, havia um tom contraditório entre as políticas de incentivo à produção cultural que partia do governo. Tais políticas apoiavam uma produção e difusão cultural, principalmente a partir da distensão proposta por Geisel, porém destacavam-se, por vezes, produções voltadas à massificação, em parte através da TV, representada pelas grandes empresas de comunicação. No entanto Napolitano (2001, p.102), em suas observações sobre a cultura brasileira durante a ditadura, sugere alguns fatores que interferiram nessa ação em prol da cultura. Em primeiro lugar, o abrandamento do regime interferiu na censura, tornando-a mais leve em determinados casos, além disso, havia uma intenção em proporcionar uma integração nacional através da cultura e em preservar tradições e o folclore nacional. Um terceiro aspecto colocado pelo autor tange a participação de artistas e intelectuais nas ações do governo relativas à cultura.

Enquanto os órgãos militares e de segurança mantinham uma lógica de controle, repressão e vigilância, muitos órgãos da cultura eram dirigidos por pessoas ligadas às artes e ao meio intelectual, sobretudo após 1975, como Roberto Farias, na Embrafilme ${ }^{2}$, e Orlando Miranda, no SNT ${ }^{3}$. Esses nomes eram elos entre o Estado e a classe artística, desempenhando um papel de mediadores das tensões entre um e outro. (NAPOLITANO, 2001, p. 102-103).

2 Empresa Brasileira de Filmes

3 Serviço Nacional de Teatro. 
Face ao desenvolvimento da indústria de bens simbólicos, a identidade nacional acaba por colocar-se como um ponto a ser debatido, em sentido político e socialmente. Logo, a partir dessa preocupação em torno de uma integração nacionalista, surge o Plano Nacional de Cultura (PNC), este voltado, sobretudo, para termos nacionais, para a conservação de memória e tradições populares e para a valorização do folclore.

O próprio documento de Política Nacional de Cultura, que integra boa parte da ideologia do $\mathrm{CFC}^{4}$, considera como seu objetivo primeiro "conservar o acervo constituído e manter viva a memória nacional, assegurando a perenidade da cultura brasileira". O argumento da tradição é fundamental para a orientação de uma política do Estado que se volta para atividades como "pró-memória", "museu histórico", "projeto memória do teatro brasileiro", "dia do folclore", etc. (ORTIZ, 2012, p. 97. Grifos do autor).

Logo a institucionalização da cultura mostrar-se-ia como uma maneira possivelmente útil de impor a presença do Estado na produção cultural. Napolitano ressalta ainda que o PNC "[...] revela as várias faces, muitas vezes paradoxais, da relação entre o regime e a cultura." (NAPOLITANO, 2001, p. 104). Dessa forma a política de abertura mantinha sua caminhada "lenta, gradual e segura", conforme as palavras de Geisel, oscilando entre abrandamento e recrudescimento da repressão.

No entanto, uma ação entre artistas e intelectuais voltou-se para a ocupação dos espaços que eram abertos pela política cultural proveniente do governo. Dessa forma alguns acreditavam na abertura de novas possibilidades de divulgação de conteúdos politizados, mesmo que minimamente, a um número maior da população através da grande mídia. Napolitano lembra que a televisão, apesar de difundir largamente uma cultura massiva, mantinha contato com profissionais, muitas vezes ligados à esquerda, estes "[...] tentavam criar uma atmosfera de reflexão nos telespectadores." (NAPOLITANO, 2001, p. 90). Além disso, a perspectiva de integração nacionalista e valorização da cultura brasileira configuravam-se num ponto de convergência entre Estado, mercado e esquerdistas.

A aproximação de Geisel com artistas e intelectuais de vertente esquerdista configurou-se em alguns pontos como sendo de interesse comum entre os dois lados, ou seja, a valorização do nacional em detrimento do estrangeiro, o vislumbre de uma possibilidade maior de atuação por parte dos artistas, além de uma aproximação entre estes e o governo militar. No entanto, a visão do governo de certa forma divergia da visão dos oposicionistas no aspecto de definição de cultura popular, enquanto o primeiro entendia-a como tradição, folclore, o segundo tomava-a no sentido de uma cultura até certo ponto conscientizada dos problemas sociais enfrentados pelas classes menos favorecidas. Essa concepção viria de certa forma a reforçar uma dicotomia entre popular e erudito.

Tal concepção legitimaria a existência de uma dicotomia estrutural da sociedade; por um lado teríamos uma elite que se consolidaria como fonte e promulgadora do "progresso"; por outro, as classes subalternas que representariam a permanência de formas culturais que arqueologicamente se acumulariam enquanto legado de um passado longínquo. (ORTIZ, 2012, p. 70. Grifo do autor).

4 Conselho Federal de Cultura. 
De um modo geral, pode-se considerar, talvez, a posição de artistas e intelectuais relativa às questões políticas propriamente em confluência com a própria experiência artística, ou seja, a postura assumida pelos representantes de uma forma de experiência cultural coloca-se diante dessa problemática socioeconômica de forma reflexiva. Nesse espectro contraditório que se formulou o campo cultural na década de 1970, a crítica social e política assumem, talvez, mais uma face contraditória ao utilizar como forma de contestação o próprio ambiente da grande mídia, como o caso do suplemento Anexo onde se viam manifestações críticas ao político e social inseridas em um veículo de comunicação de grande porte como o Diário do Paraná.

\section{O Suplemento Anexo}

O Anexo, idealizado por Reynaldo Jardim (1926-2011) e editado por ele e Marilú Silveira, surgiu num período em que a sociedade ainda vivia sob o fantasma da ditadura militar. Apesar disso, segundo Teixeira (2000, p. 375) era tido na época como um dos principais meios de divulgação e produção cultural de Curitiba. Iniciou sua circulação no dia 27 de junho, "Seis meses depois, o suplemento era visto como 'o instrumento mais importante de instigação cultural da cidade' [...]". (TEIXEIRA, 2000, p. 375. Grifo da autora). Sua configuração apresentava-se inovadora, as publicações iam muito além da simples exposição de acontecimentos culturais ocorridos pela cidade. $O$ desenho de humor ocupava lugar de destaque em suas páginas.

Entre os diversos temas abordados nas charges, caricaturas e cartuns, a TV, um dos meios de comunicação de massa que se popularizou largamente na época, aparece sob uma ótica reflexiva e questionadora entre o conteúdo despolitizado oferecido pela programação e a posição passiva assumida pelo telespectador. O comportamento social, moralista e alienado, também surge entre os temas representados ironicamente no Anexo. As notícias apresentadas no suplemento eram quase sempre acompanhadas por algum desenho, humorístico ou não, exemplo disso, a coluna Papo Jornal, publicada sistematicamente que trazia informações gerais, algumas delas seguidas por desenhos. Havia ainda as colunas específicas de humor, como o Jornal de Humor, publicada aos domingos, e a coluna diária Humordaça.

\section{Humor gráfico como forma de contestação}

A linguagem gráfica de humor reflete sobretudo um pensamento. Subjetivo ou não, seu significado transcorre nas entrelinhas da comicidade, num processo crítico e reflexivo complexo. Desse modo caricaturas, charges, cartuns por vezes constituem-se num meio pertinente de comunicação por vias oblíquas, diria até. Nesse sentido, a denúncia de abusos autoritários passaria a ser uma das questões centrais da temática de muitas das produções nessa área. Assim, entre as diferentes formas de significar, a linguagem gráfica humorística atua também através de uma espécie de ausência do imediatismo, ou seja, a realidade factual surgiria de um modo mais sutil em relação ao que é representado pelo desenho. Trataria, sobretudo, de uma ausência de concretude na configuração do tema abordado; de um objeto ou ação humana, representados, por vezes, de modo alegórico, através de inversões ou mesmo 
numa forma que transcende o próprio significado pretendido, e o que se desejaria transmitir não se revelaria na superfície, mas sim na profundidade significante.

Em sentido formal o cartum possibilita uma visão da realidade de um modo transcendental ao generalizar, por vezes, o tema retratado, atuando como expressão gráfica capaz de encerrar na imagem todos os elementos significativos que possa apresentar, uma vez que "[...] realiza-se plenamente através de seus limites. Limites que são técnicos e que são gráficos." (CIRNE, 1982, p. 87). Caracterizado ainda por uma "transverbalidade", ou seja, apresenta-se não só como imagem, mas também como algo que comunica através da imagem, numa concepção tomada num sentido de confluência entre imagem/visualidade e linguagem/verbal. Essa transverbalidade marca o cartum como um elemento que causa, de certo modo, um impacto visual e cognitivo significativo, trataria então de uma "situação-limite" entre o humor, o riso, e seu significado crítico, implícito e sério (CIRNE, 1982, p. 88).

Tomado num sentido amplo, uma resistência em face a sistemas normativos, tanto no meio artístico como na própria vivência em sociedade, configurava-se numa das formas de reação contra o autoritarismo presente naquele momento, como mencionado anteriormente. Tal interesse por parte também de artistas e intelectuais por formas ditas marginais e alternativas de atuação e produção artística, cresceria justamente num momento em que uma política cultural oficial era oferecida à sociedade, porém, mais direcionada a uma massificação cultural do que de uma valorização intelectual, como revelaria Hollanda (1981, p. 96). Trata-se aqui de uma das direções em que a crítica anticonservadora atuava, reagindo de certa forma contra a alienação e a moralidade social vigentes na época. O desenho de humor conecta-se a essa reflexão crítica num caráter irreverente e satírico de contestação, não apenas à política,

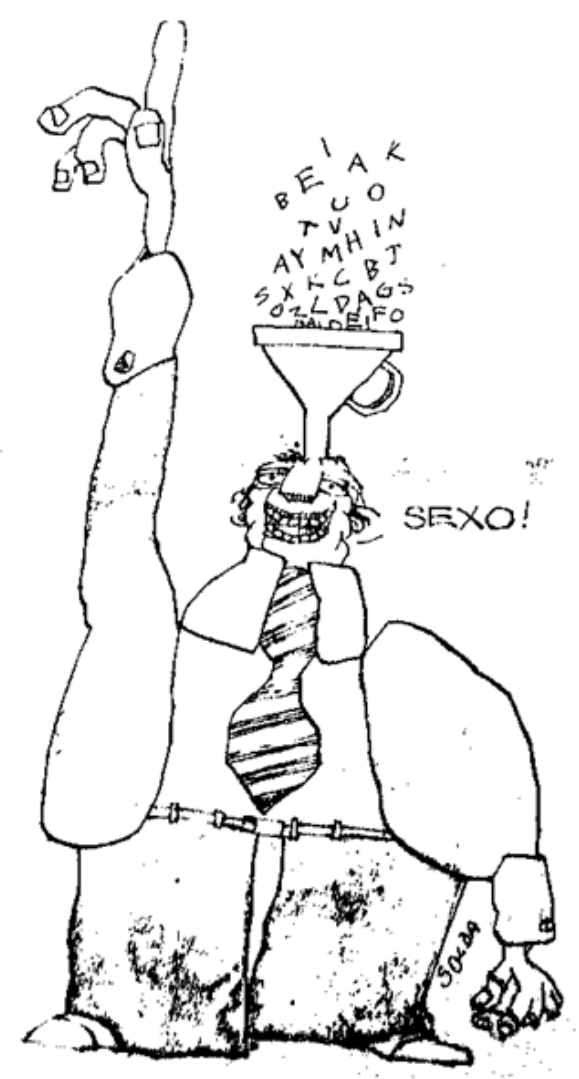


O primeiro desenho apresentado aqui trata-se de um desenho de autoria de Luiz Antônio Solda. Num olhar superficial seu significado refere-se de imediato a uma questão comportamental. Um senhor é representado de terno, gravata com um funil sobre sua cabeça por onde várias letras aleatórias entram em sua mente, tomando conta dela, ao lado aparece a expressão "SEXO!". A problemática lançada a partir dessa observação poderia ser entendida no sentido de um questionamento da conduta social. Parte da indumentária do sujeito direciona-se, subjetivamente, diga-se, para uma compreensão em torno da seriedade inserida em seu comportamento diante da sociedade - o senhor, chefe de família, com um cargo profissional de alguma importância, mas que reage inesperadamente diante do fluxo incessante de informações que chegam até ele através dos mais diversos meios. Sua expressão facial revela certo sentimento de satisfação quando the vem à mente a palavra "sexo", única que ele conseguiria distinguir em meio a tantas outras sem o mesmo significado para ele. $O$ sujeito tem o braço esquerdo levantado e o dedo indicador aponta para cima, aliada essas observações à expressão facial, o desenho torna-se representativo também de alguém que acaba de ter uma ideia, uma boa ideia.

Depois de um dia cheio, trabalhando para manter uma determinada imagem social, ainda que superficialmente, uma ideia lhe vem à cabeça - o sexo como forma de relaxar - contrariamente à imagem que tenta sustentar diante de uma sociedade conservadora que não aceitaria o pensamento erótico. Assim a mera sugestão do erotismo ou sexualidade manifesta no desenho atuaria como uma espécie de (mal) dito no sentido de evidenciar aquilo que se quer escondido, "[...] o não-dito capaz de revelar, de forma sensível - quando se manifesta através da arte -, o lugar do (mal) dito."(CIRNE, 2000, p. 107). Num contexto em que se configurava contraditório e em transformação econômica e cultural, como o brasileiro durante a década de 1970, 0 humor acabaria por surgir como um mecanismo de denúncia ao valer-se, em certa medida, de uma postura irônica e ambígua e, como num jogo de esconde-esconde, mostrar uma realidade incoerente quanto o próprio desenho de humor. A realidade do "cidadão de bem" que na sua individualidade também se revela em contrariedade ao sistema de regras impostas verticalmente e incessantemente sobre sua mente, invadindo-a, porém sem dominá-la por completo, deixando brechas para que o próprio sujeito se realize de acordo com suas vontades, ainda que subjetivamente.

O humor gráfico, num direcionamento contestador, atuou, e ainda atua, num teor reflexivo imanente a sua construção. Assim, unido a sua consciência política, coloca-se como uma expressão diante das relações sociais de modo a questiona-las.

Ao se valer dos mecanismos da cultura de massa, o quadrinheiro, a rigor, compromete-se política e socialmente com o tempo histórico que marca a sua existência enquanto ser concreto no interior das classes sociais, assim como se compromete ao recusar esses mesmos mecanismos. De uma forma (dentro da cultura de massa) ou de outra (à sua margem), o artista de quadrinhos só tem um compromisso: com a realidade. Este compromisso, decerto, não se esgota em um realismo estreito, de cunho idealista. (CIRNE, 1982, p. 23).

O autor ainda refere-se ao humor gráfico contestador fundamentado numa rejeição também aos modelos impostos pela cultura de massa baseados, em partes, nos quadrinhos americanos, numa referência à "estética da fome": "Investir numa estética 
da fome significa que é necessário assumir a nossa latino-americanidade, posicionando-se politicamente contra o quadrinho enlatado, de padrão disneal." (CIRNE, 2000 , p. 44. Grifo do autor). Desse modo, entender o humor como uma ironia contestadora das normas vigentes torna-se plausível na medida em que, ao mesmo tempo em que se propunha uma seriedade nas produções, através de políticas oficiais e, também, a sociedade buscava uma conduta dita séria, o humor gráfico possibilitaria uma reflexão através de seu caráter cômico, satirizando essas condutas.

Quanto à relação oposicionista entre artista e sistema sociopolítico, no caso aqui analisado, é possível observar certa postura questionadora do cartunista Solda, que, ao representar um senhor, insere um aspecto cômico ao relaciona-lo ao desejo sexual, este como algo que permanece encerrado em seu pensamento. Nesse sentido a crítica recairia sobre um comportamento que segue normas racionalizadas impostas por um sistema opressor, onde desejos dessa ordem devem ser reprimidos. Uma das características do desenho de humor é justamente a possibilidade de se colocar em posição controversa em ambientes repressivos por meio da subjetividade alcançada em parte através de seu caráter irônico, uma vez que este desviaria a atenção primeira de quem o observa. "As estórias em quadrinhos procuram 'ocultar' a verdadeira ideologia através de fórmulas temáticas muitas vezes simples ou simplistas, fazendo da redundância [...] o lugar de sua representação: [...]." (CIRNE, 1982, p. 11).

A atitude contestadora assumida por artistas e intelectuais é antes explanada por Williams (1969, p. 57). O autor, porém, analisa a relação de oposição à mercantilização da arte no século XIX a partir da postura de escritores da época. Desse modo, segue-se para uma observação sobre o ato de negação em face à industrialização crescente por parte desses escritores, fato tal que resultaria na ideia de arte como elemento superior, de modo que a cultura passaria a ser dividida em erudita e popular. Nesse sentido ainda é possível constatar um vínculo entre política, sociedade e arte/artista e a posição deste último do ponto de vista social, onde as transformações ocorridas nas primeiras - política e sociedade - implicariam em influências no âmbito da cultura. Além da própria atitude de negação formar um elo na perspectiva proposta aqui, tanto por parte dos escritores do século XIX, como pela postura de recusa à racionalização da experiência humana evidenciada no desenho.

Nesse sentido ainda, Williams (1969, p. 59) sugere uma complexidade maior sobre a própria oposição arte/política; arte/sociedade. A arte reflete também valores sociais, humanos acima de tudo. O protesto político e social através da cultura assume, pode-se dizer, conotações diversas de acordo com o ambiente e a temporalidade em que se encerra.

\section{A crítica social e a cultura de massa}

A expressão cultura de massa pode remeter, num primeiro momento, a algo inferior, de baixa qualidade e de senso comum. Williams (1969, p. 306-307) sugere uma definição no âmbito da cultura popular como algo voltado ao povo, porém não totalmente despolitizado. Segundo o autor as preocupações com os movimentos 
populares assinalaram três períodos distintos. O primeiro, de 1790 a 1870, em que havia uma atitude social voltada às forças novas que surgiam ao redor do industrialismo e da democracia; o segundo, entre 1870 e 1914 uma atenção maior volta-se às ações relacionadas à arte e à política; o terceiro momento coincide com o início da Primeira Guerra Mundial com maior ênfase já para os meios de comunicação de massa, que se fortalecem em 1945, já então no término da Segunda Guerra Mundial, coincidindo com avanços consideráveis na área da tecnologia.

Sendo assim, o fenômeno da massificação pode ser compreendido, entre outros fatores, como uma consequência acima de tudo histórica, uma vez que remete à Revolução Industrial que mostrava já os primeiros indícios de uma aglomeração populacional nos grandes centros urbanos, esta tenderia a crescer em virtude, sobretudo, da industrialização e da modernização dos meios de comunicação de grande alcance. Desse modo a alta concentração de habitantes nas cidades devido ao desenvolvimento industrial, e a formação da classe trabalhadora, configurariam uma tendência social que confirma de certa forma o sentido de massificação tanto social como política. Quanto ao significado da expressão massa relacionada à concentração popular o autor sugere que:

Embora massa fosse palavra nova para indicar multidão, populaça, conservava, em seu sentido, as características usualmente associadas ao vocábulo antigo: credulidade, volubilidade, preconceitos de grupo, vulgaridade de gosto e hábitos. As massas, encaradas desse modo, constituíam perene ameaça para a cultura. Pensamento de massa, sugestão de massa, preconceito de massa ameaçavam afogar o pensamento e o sentimento individual qualificado. Até a democracia, com sua reputação clássica e liberal, perderia o seu sabor, transformando-se em democracia de massa. (WILLIAMS, 1969, p. 308).

Desse modo seria possível uma aproximação às razões pelas quais o governo brasileiro e a classe dirigente desejavam inserir o povo dentro de uma concepção de cultura que deveria se manter controlada, dominada. Assim a cultura de massa entraria num espectro de manipulação em favor da ordem dominante. $O$ incentivo do Estado em relação a uma produção cultural voltada às massas permaneceria ligado ao objetivo da alienação e conformação diante da condição inferior lhes atribuída.

Nessa direção, o segundo desenho que apresentamos aqui, de autoria de Luiz Carlos Rettamozo, mostra uma cédula de identidade com todos os itens de identificação de um suposto portador, porém o espaço destinado para a foto é preenchido por um busto masculino, perceptível pela presença da gravata, em ausência do rosto do sujeito. Tal detalhe, além do caráter cômico atribuído ao mostrar o inusitado, oferece uma variedade de interpretações. Entre elas, possibilita uma analogia ao crescente interesse pela grande mídia e a consequente massificação por parte dos telespectadores, uma vez que um dos objetivos residiria sobre a manipulação da opinião. 


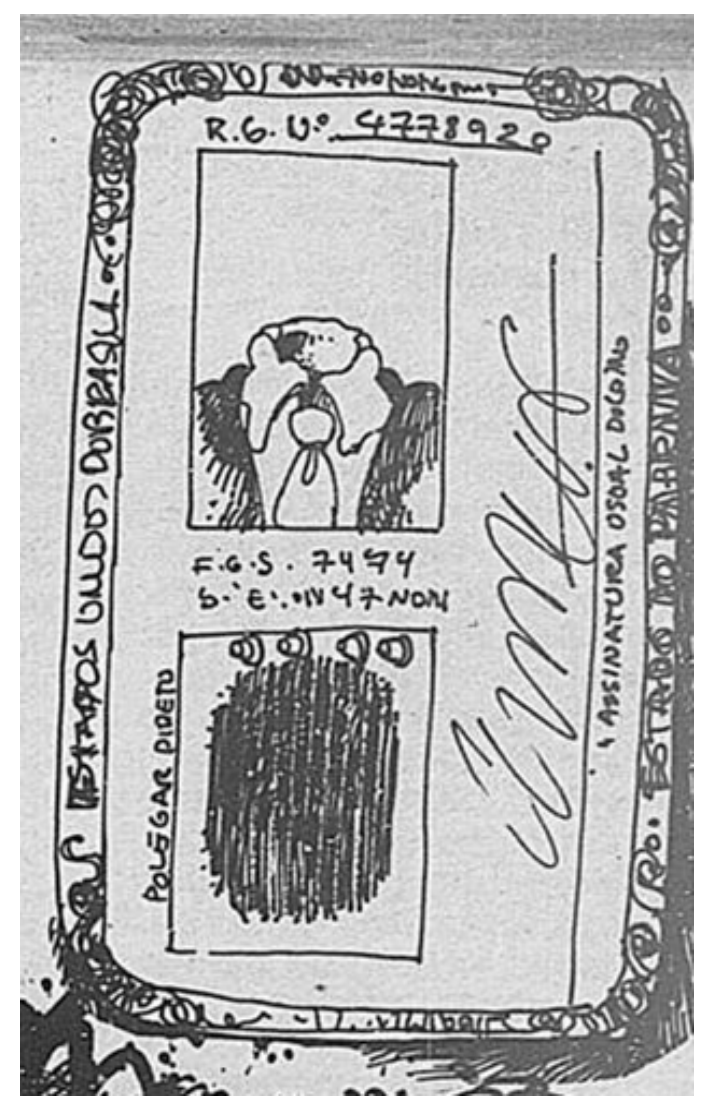

RETTAMOZO, Luiz Carlos. Diário do Paraná - Anexo. Curitiba, 28 de julho de 1977.

A ausência da cabeça do sujeito, se considerado o que foi explanado aqui, direciona o entendimento para uma relação à alienação, pois é possível estabelecer um vínculo com a falta de pensamento, de senso crítico, uma vez que as faculdades intelectuais do ser humano são ligadas ao cérebro - neste caso se não há cabeça, não há cérebro, ou a presença de qualquer atividade cognitiva. A falta deste órgão reforçaria então a relação ao senso comum acrítico e passivo recorrente numa sociedade massificada possibilitada, em grande parte, pela mídia voltada ao mero entretenimento e despolitizada. A representação sugeriria assim que o portador do documento não possui a capacidade de ao menos pensar reflexivamente.

Por outro lado, outro ponto contraditório dentro desse incentivo à cultura - cultura de massa - pelo Estado militar é justamente a manutenção da censura, no entanto esta quando aplicada aos meios de comunicação de massa funcionava de forma seletiva. Ortiz refere-se a tal como um "[...] ato repressor que atinge a especificidade da obra, mas não a generalidade da sua produção." (ORTIZ, 2012, p. 89). Assim sua interferência recaía, em grande parte, sobre o conteúdo reflexivo e politizado da produção, sem tocar nos programas direcionados à mera distração, reforçando o caráter de alienação e manipulação. Deste modo, outra possibilidade interpretativa ao desenho abre-se à atribuição de um aspecto vazio, representado então pela ausência do rosto do sujeito na cédula de identidade. Vazio tanto de senso crítico em relação ao que é veiculado pela mídia, como também ao autoritarismo opressor exercido na época, como a própria censura que limitava a informação que chegava ao leitor/espectador. 


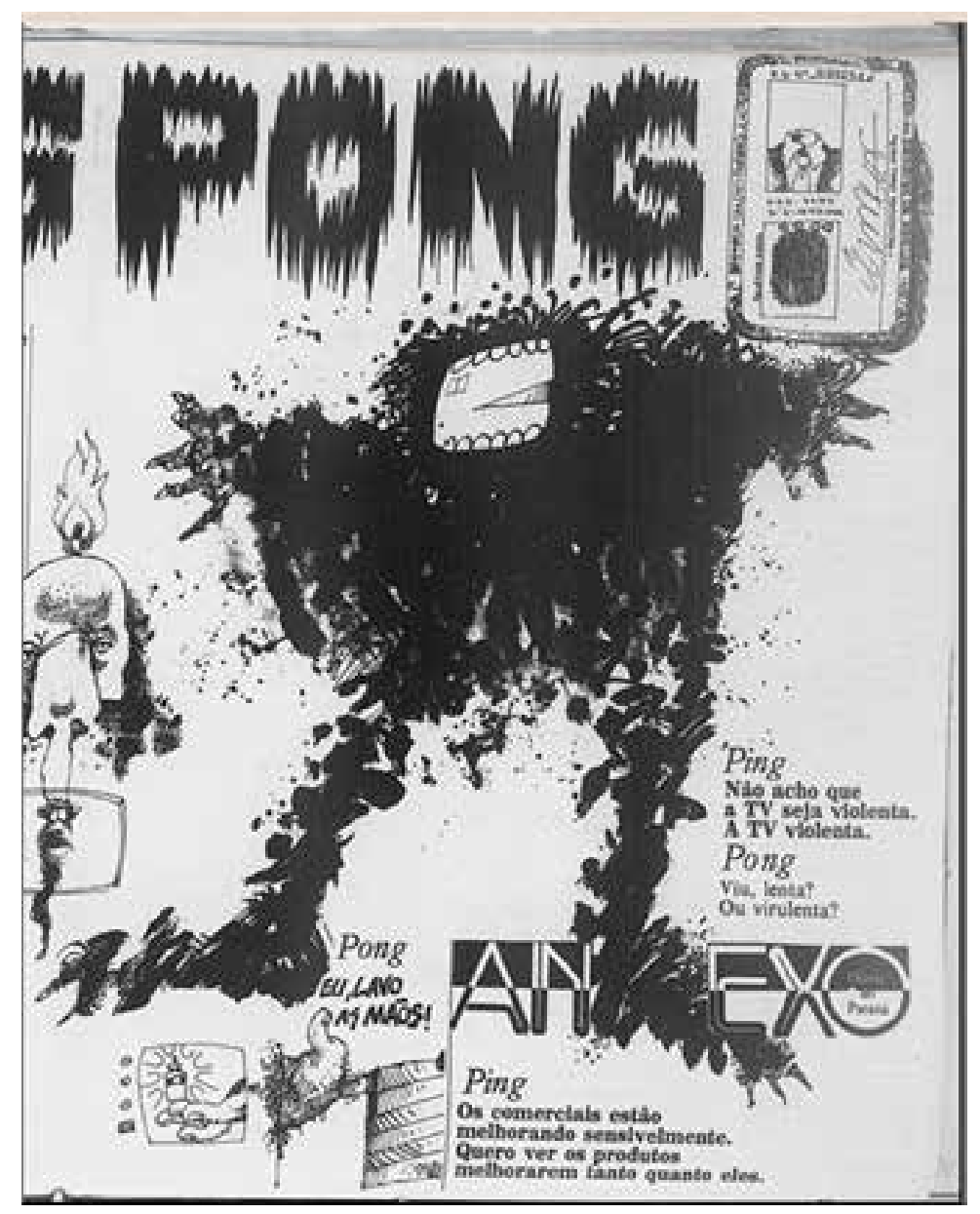

RETTAMOZO, Luiz Carlos. Diário do Paraná - Anexo. Curitiba, 28 de julho de 1977.

Em relação ao conteúdo significante do cartum de Rettamozo, a crítica à TV como mídia alienante e massiva fica de certa forma explícita ao observar a página do suplemento em que ele aparece. Nela é possível perceber outras referências à TV, tanto nos desenhos que a compõe - também de autoria de Rettamozo - como nos textos que questionam sua programação ${ }^{5}$. O desenho central apresenta um ser cuja configuração grande e disforme atribui-lhe aspecto um tanto assustador, além disso, surge com o que se poderia entender como uma TV no lugar do rosto, fato esse que lhe atribuiria talvez um ar vazio, tanto sentimental como intelectualmente, imerso em sua insignificância, passivo diante das complexidades e transformações que direcionam a sociedade para uma modernidade planejada e linear, sem aberturas para a livre criação da própria experiência temporal e cognitiva. O caráter monstruoso da figura poderia se relacionar quem sabe a certa atitude ameaçadora da TV, em sua tarefa de manipular as pessoas. O espectador, por sua vez, também poderia ser reconhecido no mesmo desenho como um ser descontrolado, imerso em sua própria alienação. A face do "monstro", ocupada por uma TV, atribui um ar vazio ao personagem, tanto sentimental quanto intelectual, uma vez que não possui uma identidade definida e nem posição política esclarecida.

Porém, a mídia televisiva acabava por adentrar a consciência do indivíduo numa mescla entre realidade e ficção, logo a falta da cabeça na identidade, neste caso, 
poderia, por uma via contraposta à anterior, definir-se em uma espécie de recusa em aceitar as influências advindas da cultura televisiva, mesmo em desejo oculto ou como mera lembrança de um passado não muito distante, pois se considerarmos o sujeito portador da cédula como sendo o "macacão", este mantém a cabeça tomada pela TV na sua atualidade, mas outrora não era assim, esse indivíduo teria sido um humano sem qualquer interferência de ações externas, dono de seus próprios anseios e convicções, ou seja, o que não existia era uma cultura massificante dotada de poder para tomar o lugar de sua mente.

Ainda no tocante à cultura nesse período, Ortiz (2102, p. 88) lembra que o Estado atribuiu às empresas privadas o controle administrativo dos meios de comunicação e manteve para si o domínio de outras instituições culturais, direcionadas, sobretudo, ao teatro com a fundação do Serviço Nacional de Teatro (SNT), ao cinema através da Embrafilme, à literatura com o Instituto Nacional do Livro e à arte e folclore com a Funarte ${ }^{6}$. Por outro lado, assegurava ainda um comando em última instância da transmissão de informações pela mídia ao fornecer os meios necessários, em termos de infraestrutura, ao seu desenvolvimento, pois assim mantinha a produção cultural atrelada ao governo.

A ideologia da segurança nacional, que está na origem da política da telecomunicação no Brasil, se prolonga, desta forma, enquanto controle ideológico e político. O espaço de atuação das empresas privadas encontra-se, assim, delimitado pelos critérios que orientam as atividades do Estado autoritário [...]. (ORTIZ, 2012, p. 88).

No sentido à cultura de massa dado por Williams (1969), já relatado brevemente, é possível compreender que a caracterização de uma cultura de massa reside na capacidade de atingir um grande número de pessoas ao mesmo tempo. Sendo a TV então um dos principais meios de comunicação, difundida amplamente na década de 1970, o interesse sobre a mídia televisiva partiu tanto do governo, que via ali uma possibilidade de legitimação do sistema político imposto pelo regime, como também por parte das empresas de telecomunicação, pois estas puderam contar com um apoio do Estado, tanto em termos financeiros como de desenvolvimento tecnológico.

Uma das questões levantadas por Ortiz (2012, p. 90-106) em relação à cultura brasileira no período militar revela certo antagonismo referente ao interesse sobre o desenvolvimento cultural em consonância com a preservação da identidade nacional. Ou seja, o Estado apoiava uma liberdade de expressão, desde que esta se colocasse dentro da definição nacionalista imposta por ele. Desde o início da ditadura, a cultura configuraria um ponto de tensão para os militares, estes a viam como um campo subversivo.

Por outro lado, em referência ao processo de hibridação, ou reconfiguração da cultura, Canclini (2013, p. XXII) ainda cita Bourdieu o qual define o conceito de "reconversão" onde mudanças de hábitos, estratégias e condições de atuação - como as condições dos artistas após o golpe em 1964 - exigiriam uma adaptação ao novo meio oferecido. Nesse sentido, ainda em concordância em parte com autor, seria possível concluir que o âmbito cultural e social não nasce isolado, mas sim de com-

6 Fundação Nacional de Artes. 
binações diversas, principalmente de questões políticas, que de alguma forma já fazem parte das interações socioculturais. Assim torna-se pertinente considerar em certa medida o próprio desenho de humor como uma estratégia de adaptação à nova realidade.

A partir da nova configuração da realidade, o desenho de humor se mostraria capaz de atuar como meio de expressão importante face à repressão, utilizando por vezes linguagens em confluência - como o uso simultâneo de imagem e texto - e socioculturais ao partir da posição intelectualizada da arte para atingir as mais diferentes camadas sociais, através de uma confluência entre o erudito e o popular, este, no entanto, representado pelo próprio desenho de humor, além de recorrer à mídia de massa para veicular sua opinião. "As buscas artísticas são chave nessa tarefa, se conseguem ao mesmo tempo ser linguagem e ser vertigem." (CANCLINI, 2013, p. XL).

Se tomado ainda o desenho humorístico poderíamos pensa-lo, quem sabe, como um meio em essência massivo, mas com capacidade para desequilibrar a base hegemônica do sistema político ao trata-la por um viés irônico, sob um olhar enviesado, voltado à crítica de sua própria função enquanto meio comunicacional. Logo, o que tentamos problematizar aqui, em parte, é como determinados artistas se colocaram diante desse contexto por meio da exploração do desenho de humor como forma de se "infiltrar" no sistema dominante, e assim produzir tensões entre as duas frentes culturais: estética e massiva. Nesse sentido, Canclini (2013, p. 134) percebe que a atuação artística em meio a ambientes aparentemente desconexos implicaria uma permanência no limite das tendências como "artistas da ubiquidade" que se deslocam simultaneamente pelas fissuras da normalidade. Nesse sentido se constituiria talvez um dos pontos da hibridação cultural, ao colocar lado a lado a margem e o centro como vias de questionamento, tanto de um ambiente como de outro.

Por outro lado, a interpretação quanto ao significado da representação pode vir a se tornar ambígua no sentido de que espaços são deixados em aberto pelo artista, possibilitando assim uma reorganização das ideias por parte do observador que traduz, talvez, sua particularidade em entendimento acerca do significado implícito na obra. Seria então conveniente, por assim dizer, que uma produção artística voltada ao questionamento e à contestação em um ambiente autoritário, como o desenho de humor, fosse realizada através de traços que remetessem a uma simplicidade aparente, porém com um significado bem mais complexo implícito nessa configuração irônica.

Dentro do que foi exposto até aqui, a crítica social através da cultura seria apenas uma maneira de expressar-se. Este ensaio buscou refletir sobre um modo de questionamento acerca das conexões entre cultura e a política na esfera social. $O$ desenho de humor, por sua vez, atua subjetivamente como parte dessa reflexão em torno da cultura, da contestação, da crítica. Seria possível, então, esboçar como uma breve conclusão que os diferentes aspectos da crítica social, como respostas aos processos evolutivos culturais face a um movimento de transformação contínuo da sociedade como campo político e cultural, atuaram, e ainda atuam, em nome de um desejo quase libertário, por assim dizer, uma vez que os limites impostos às manifestações, não só políticas como culturais, passou a ser entendida sob uma ótica da transgressão e, acima de tudo, da comunicação, mesmo que velada, dos abusos cometidos por governantes num sentido geral. 


\section{REFERÊNCIAS}

CANCLINI, Néstor García. Culturas híbridas: estratégias para entrar e sair da modernidade. 4 ed. São Paulo: EDUSP, 2013.

CIRNE, Moacy. Quadrinhos, sedução e paixão. Petópolis, RJ: Vozes, 2000.

Uma introdução política aos quadrinhos. Rio de Janeiro: Achiamé / Angra, 1982.

COELHO, Cláudio Novaes Pinto. A contracultura: o outro lado da modernização autoritária. In: Anos 70: trajetórias. Vários autores. São Paulo: lluminuras: Itaú Cultural, 2005.

FREITAS, Artur. Arte e contestação: o salão paranaense nos anos de chumbo. Curitiba: Medusa, 2013.

HOLLANDA, Heloísa Buarque de. Impressões de viagem: CPC, vanguarda e desbunde 1960/70. São Paulo: Editora Brasiliense, 1981, 2ª ed.

NAPOLITANO, Marcos. Cultura brasileira: utopia e massificação (1950-1980). SP: Contexto, 2001.

ORTIZ, Renato. Cultura brasileira e identidade nacional. São Paulo: Brasiliense, 2012

TEIXEIRA, Selma Suely. (org.). Jornalismo cultural: um resgate: Aramis Millarch, José Carlos (Zeca) Corrêa Leite, Reynaldo Jardim. Curitiba: Gramofone, 2000.

WILLIAMS, Raymond. Cultura e sociedade: 1780-1950. São Paulo: Editora Nacional, 1969, 3ㄹ ed. 